\title{
The use of storytelling in quantitative research reports: A marketing research firm perspective
}

\author{
Authors: \\ Vanessa Maritz \\ Daniel J. Petzer ${ }^{1}$ \\ Christine De Meyer \\ Affiliations: \\ ${ }^{1}$ Department of Marketing \\ Management, University of \\ Johannesburg, South Africa \\ Correspondence to: \\ Christine De Meyer \\ Email: \\ cfdemeyer@uj.ac.za \\ Postal address: \\ PO Box 524, Auckland Park \\ 2006, South Africa \\ Dates: \\ Received: 11 Dec. 2013 \\ Accepted: 11 Feb. 2014 \\ Published: 18 July 2014 \\ How to cite this article: \\ Maritz, V., Petzer, D.J. \& De \\ Meyer, C., 2014, 'The use of \\ storytelling in quantitative \\ research reports: $A$ \\ marketing research firm \\ perspective', Acta Commercii \\ 14(2), Art. \#248, 10 pages. \\ http://dx.doi.org/10.4102/ \\ ac.v14i2.248

\section{Copyright:} \\ (C) 2014. The Authors. \\ Licensee: AOSIS \\ OpenJournals. This work \\ is licensed under the \\ Creative Commons \\ Attribution License.
}

Orientation: Actionable reporting ensures that a marketing research firm communicates with clients to achieve business impact as opposed to merely communicating data to clients. Storytelling communicates with impact as it focuses on creating engagement and inspiring action.

Research purpose: This article investigates the use of storytelling as a tool for actionable reporting by South African marketing research firms

Motivation for the study: Clients of marketing research firms often criticise research reports as being too technical and lacking in strategic value. Storytelling is a reporting technique that can be used to develop actionable research and provide clients with more strategic value.

Research design, approach and method: A total of 26 in-depth qualitative interviews were conducted with client service directors and managers of marketing research firms that deliver quantitative research reports to clients.

Main findings: Results indicated that all marketing research firms but one use storytelling. Barriers that impede more regular use are inexperienced research executives and the time intensity associated with creating stories.

Practical/managerial implications: Storytelling should be used by marketing research firms to provide clients with more actionable research.

Contribution/value-add: The study provides marketing research firms in South Africa with recommendations as to how to implement storytelling as a reporting technique, which will add value to clients and enable marketing research firms to remain competitive and develop relationships with clients.

\section{Introduction}

The Information Age is characterised by information overload and difficulty experienced in making sense of data (Doyle \& Tharme 2011). It is therefore important for marketing research firms to break through information clutter when presenting research results to clients (Doyle \& Tharme 2011). Marketing research firms often provide masses of data that, in many cases, have limited insights, practical use and strategic value (actionability) for clients (Digit 2011). Many clients still fail to see the impact of the research on their businesses and how research assists sound decision-making. This limited assistance in interpreting data has led to many clients having poor perceptions of marketing research firms, which can be damaging to the industry as a whole (Moran 2010; Von Bormann 2000).

To warrant future business and increased revenues, marketing research firms need to position themselves as professionals who can deliver actionable research results that assist clients in sound decision-making (Doyle \& Tharme 2011; Moran 2010:14). Consequently, a renewed focus on the subject of how to provide actionable reports is needed (Bain 2011). To deliver actionable reports and therefore enable clients to act on research results, marketing research firms need to have an appealing and engaging communication and report approach (McCall, Rabson \& Dimopoulos 2004:9; Precourt 2010:3). This can be achieved through a number of methods, one of which includes storytelling (Lewis 2010:9; Micu et al. 2011:10). Storytelling is defined as giving account of something in a specific order that creates connection between data or facts (Segel \& Heer 2010:1).

This article comprises a literature review, an exposition of the problem at hand, research objectives and a discussion of the methodology used to conduct the research. Finally the results, the implications thereof and limitations of the study are presented. 


\section{Literature background The marketing research industry}

The South African marketing research industry is highly fragmented, with 106 marketing research firms listed on Bizcommunity (2011) and approximately 80 registered with the Southern African Marketing Research Association (SAMRA 2010). However, market share analysis indicates that only a few marketing research firms dominate (based on the latest publicly available figures from 2004), with 55\% of the industry's market share in South Africa distributed amongst Nielsen, Ipsos, TNS and Millward Brown (TNS 2004). Marketing research firms that constitute a further $20 \%$ of the industry market share include firms such as Ask Afrika, Bateleur, Consulta, KLA, GfK South Africa and React Surveys (TNS 2004).

Marketing research firms face other challenges in the market such as continual client demand for faster and more costeffective research, continual technological advancements that demand that innovate solutions are offered, increased difficulty of conducting fieldwork, fierce and increased competition, skill shortages and high employee turnover within marketing research firms (Appleton 2011; Bain 2011; 2012a; GreenBook 2011:14; Moran 2010:9-14). In addition marketing research firms are still seen to provide masses of data with no or limited insights, practical use and strategic value (actionability) (Dowsett 2012; Von Bormann 2000).

\section{The need for engaging report formats}

Marketing research firms realise and understand the need that exists to report and present research results in more visually appealing, actionabe and engaging formats to clients (Bain 2011). Doyle and Tharme (2011) state that current research report formats are a 'dying breed' and a need for simpler, clearer and more insightful reports has emerged. This need can be attributed to:

- Client demand: Clients continuously pressure marketing research firms to deliver actionable research with strategic impact as opposed to large data sets (Appleton 2011; Bain 2012a).

- Competition: Marketing research consultancies are bridging the gap between supplying data and delivering insights (GreenBook 2011:14; Van Slooten \& Verheggen 2011:2, 3).

- Increased data volumes: The result of the Information Age is a wealth of data that overloads people and clients with too much information and a lack of actionable insights (Digit 2011; Doyle \& Tharme 2011; Few 2007).

Research reports are typically too long, too technical and confusing for clients to understand (Mahmoud 2004:11). The shortcomings of research reports also compromise the actionability of such reports in client decision-making and the impact such reports have on business (Zikmund \& Babin 2010:60). Research reports typically present the following problems:
- Complex information: Research reports often contain overly complicated information with no or little insights, lots of facts, technical details and sophisticated research methods (Zikmund \& Babin 2010:60).

- Too statistical: Clients often do not comprehend statistical terms, calculations or conclusions and it impedes understanding and actionability of the research results; it is also unlikely that the client will admit this to the marketing research firm (Mahmoud 2004:7, 9-11).

- Lengthy: Lengthy and detailed research reports obstruct understanding of the research results and lower the impact the research has on clients' business (Bain 2012b).

- Lack of business impact: Research reports often lack business impact by detailing the current situation around the research problem, but failing to show any direction for future action (Davison 2011:3).

- Ineffective communication: Research reports often do not report the research results in an effective manner (Bain 2012b).

All these factors affect the reporting approach of marketing research firms. Even though these problems are difficult to overcome, increasing pressure on marketing research firms exists to deliver more simplified and actionable research results. As a result, storytelling is changing the way that marketing research firms report research results and is identified as a solution to the requirement of simplified and actionable reporting (Bain 2011; Digit 2011; Micu et al. 2011:10; Segel \& Heer 2010:1). Research reports are unable to drive change in client behaviour without stories that give meaning to data (Silverman 2006:169).

\section{Storytelling's role in organisations and in delivering actionable reports}

Tobin and Snyman (2008:133) state that since the beginning of human existence, storytelling has existed. From the earliest days, storytelling has been recognised as critical to the process of learning and understanding and conceptualising a universal experience (Carter-Black 2007:32). Czarnecki (2009:5) comments on the role that technology has played in the history of storytelling: in the past, technology was used as a tool to spread stories to a wider audience; presently, it is used as a tool that is an integrated part of the storytelling process and of the story itself.

Nonetheless, storytelling is used in many different business disciplines, some of which are leadership, management, coaching, selling, education and branding (Bosworth \& Zoldan 2012; Carr \& Ann 2011:236; Silverman 2006). Organisations address various tactical and strategic business issues through storytelling, such as customer service, employees engagement, reputation management, skills improvement, teamwork development, strategic planning, corporate culture establishment and financial advising, to name a few (Carr \& Ann 2011:237, 238, 242; Mittins, Abratt \& Christie 2011:405; Silverman 2006). It is therefore increasingly being used to help firms to act consciously and purposefully when sharing information (Silverman 2006; Tobin \& Snyman 
2008:133). James and Minnis (2004) add that storytelling facilitates knowledge sharing, guides decision-making and creates commitment to change.

Storytelling has also long been recognised as useful in reporting results and is therefore relevant to the marketing research industry too. Storytelling presents a way to convey data in an actionable format that has business meaning (Grimshaw 2011:2). For the purposes of this article, storytelling is defined as focusing the marketing research firm's effort on reporting research results coherently, aiming to answer the client's business question so as to understand how the data translates to action (Cant et al. 2008:234).

An example of the successful use of storytelling is noted in Ghoshal (2011:2) where a metaphor of David and Goliath was used by a marketing research firm to deliver a research report to a client. The client's brand was associated with David who had to defeat a competitor, Goliath, by changing the rules of the game. The client could easily resonate with the story and knew what actions to take to improve the performance of their brand (Ghoshal 2011:2). Another successful storytelling example is noted in Silverman (2006:163) where a marketing research firm decided to bring Microsoft's customer segments to life by telling stories about who customers are, what they do and what they think and feel about Microsoft as opposed to merely presenting facts in traditional bar charts.

Irrespective of how it is used, several elements are needed to compile a story. These elements include the basic elements of any story: a clear beginning, middle and end are needed together with a compelling plot and characters (Lowell 2011:3, 4). Segel and Heer (2010:2) describe the basic elements of storytelling as the well-known who, what, where, when, why and how. Davison $(2011: 7,9)$, on the other hand, suggests that there is no standardised approach to storytelling; there are only departure points like data, data mining and data visualisations. It is Bosworth and Zoldan (2012:75-81) together with Ghoshal (2011:4) who provide a framework of storytelling elements:

- Setting: The setting represents the story's beginning; it is the setup that gives the context of where the story is taking place, such as at a specific market, country, consumer segment or category.

- Mission: There should always be a mission or point to the story, such as increasing the share or growth of a brand or client firm (usually linked to the research problem).
- Dilemma: These are the challenges that the characters face between the story's beginning and its turning point.

- Resolution: The story's resolution is its ending. It details how the mission should be reached, for example how to grow share despite obstacles like increased competition or changed consumer behaviour.

- Characters: A protagonist is the main character who often needs to implement the change and take action (usually the client). Antagonists on the other hand are the characters who oppose the protagonist; this is often a competitor of the client firm.

Compelling storytelling should be based on the pillars of simplicity, engagement, customisation, contextualisation, reliability and single-mindedness, as presented in Table 1.

Storytelling offers various advantages. It facilitates engaging and interactive conversations, is intuitive, stimulates the brain and aids recall, is simplified, increases impact and facilitates understanding (Carr \& Ann 2011:242; Davison 2011:12-16; Deloitte 2011; Few 2011:10; Kaidi 2012). Stories engage with people's emotions and are entertaining and therefore easy to remember (Ghoshal 2011:3). And because storytelling follows a whole-brain approach, it enables an emotional connect between clients and the research results (Silverman 2006:xxv). TNS (2010) and Hamburger and Lawry (2008:15) add that storytelling has the ability to resonate with people, whilst facts and data do not. Silverman (2006:167) adds that storytelling also offers the ability to overcome the barrier between research science and the language of business. The disadvantages of stories are that they are time intensive, that researchers are still required to know all the 'numbers' and that storytelling requires specialised skills (Davison 2011:9, 16; Silverman 2004:165). These disadvantages have a close correlation with the barriers experienced when using storytelling.

The barriers that prevent marketing research firms from adopting storytelling into research results include:

- Lack of skills: It is difficult for researchers to implement, as it goes beyond the traditional analysis role of a researcher (Davison 2011:7, 8; Thun \& Brandt 2007:14). It requires specific skills and experience to make complex data appear simple in a story format (Silverman 2006:165).

- Perception: The use of stories has a poor perception; many marketing research firms and clients think that a story is the antithesis of scientific, objective or rational research practice (Florence 2013; Ghoshal 2011:4).

TABLE 1: Pillars of successful storytelling.

\begin{tabular}{ll}
\hline Pillar & Definition \\
\hline Simplicity & Stories should help clients to absorb and understand complex data in a simple way. \\
Engagement & Stories should be engaging and interactive. \\
Customisation & Stories should be customised to the specific client audience. \\
Contextualisation & Stories should create a context against which data can be interpreted. \\
Reliability & Stories should be supported by reliable data and data visualisations. \\
Single-mindedness & Stories should be single-minded without any extra data details, as this often blurs the story. Marketing research firms should stick with the story in \\
& the research report and rather supply clients with an appendix including all charts in a data book. \\
\hline
\end{tabular}

Source: Davison (2011:3, 9, 10); Eloff (2012:12); Ghoshal (2011:3, 4); Lowell (2011:4, 5); Segel \& Heer (2010:1); Silverman (2006:141, 163, 166); White (2011)

Note: Please see the full reference list of the article, Maritz, V., Petzer, D.J. \& De Meyer, C., 2014, 'The use of storytelling in quantitative research reports: A marketing research firm perspective', Acta Commercii 14(2), Art. \#248, 10 pages. http://dx.doi.org/10.4102/ac.v14i2.248, for more information. 
- Scientific methods: Advanced scientific and statistical methods make engaging and inspiring storytelling difficult. A story fades when you have to tell it with correlation coefficients, a p-value, error terms and other statistics (Lowell 2011:3, 4).

- Costs: Major investments in soft skills and hard resources are required to develop storytelling capabilities (Bain 2011; Davison 2011:12).

\section{Problem statement and research objective}

Traditional research report formats and data visualisations (charts) are a 'dying breed'; a need for simpler, clearer and more insightful reports has emerged (Doyle \& Tharme 2011). The need for such reports emerged due to client demand, increased competition and increased data volumes (Bain 2012a; GreenBook 2011). Therefore, there is increasing pressure on marketing research firms to deliver more simplified and actionable research results. Storytelling has been identified as a solution to this requirement (Davison 2011:2; Digit 2011; Grimshaw 2011:2). Storytelling is prevalent in many disciplines and it is rapidly infiltrating the marketing research world too (Bain 2011; Lowell 2011; Shaw 2010:2). For this reason, marketing research firms are beginning to realise and understand the need to report and present research results in more engaging formats (Bain 2011; Doyle \& Tharme 2011; Micu et al. 2011:10). Against this backdrop the following problem statement is formulated for this article:

The traditional quantitative reporting by marketing research firms commonly results in large amounts of userunfriendly information that does not add value to their clients' businesses (Bain 2012b; Doyle \& Tharme 2011; Moran 2010:9-14). If alternative methods like storytelling are not adopted, marketing research firms run the risk of becoming strategically irrelevant, providing only data services and being replaced by stronger competitors (GreenBook 2011:1315; Moran 2010:14). These developments may result in lower revenues, weakened and non-strategic relationships with clients, and a loss of a competitive advantage for marketing research firms (Bain 2012b; GreenBook 2011:14; Moran 2010:9-14).

\section{Primary research objective}

To determine the extent to which storytelling is used by marketing research firms in quantitative research reports.

The primary objective will be achieved by examining how marketing research firms use storytelling in quantitative reports, by exploring perceived barriers to using storytelling in quantitative research reports and by presenting a number of recommendations that can facilitate the effective use of storytelling by marketing research firms.

\section{Research methodology}

To collect the required data, this study included both secondary and primary research. Information was collected by means of a literature review for the secondary research. For the primary research, an empirical study amongst South African marketing research firms and clients was conducted to gather information.

The empirical study was qualitative in nature and therefore an explorative research design was followed. The researchers wanted to gain an in-depth understanding of how marketing research firms in South Africa use storytelling as opposed to validating facts. Data was collected from qualifying participants (client service directors, executives and managers who oversee or work with quantitative reporting processes within marketing research firms) by means of indepth interviews. The sampling frame consisted of marketing research firms listed in the 2011 SAMRA classifieds that deliver quantitative research reports to clients (SAMRA 2011); the researchers also considered revenue contribution. The aim was to have a combination of small, medium and large marketing research firms (in terms of revenue contribution) so as to achieve some level of industry representation. The seven biggest revenue contributors and a few (eight) smaller revenue contributors were included. In alphabetical order, these were: Added Value, Ask Afrika, Aztec, Bateleur, Consulta, GfK South Africa, KLA, Ipsos, Markdata, Millward Brown, Nielsen, React Surveys, TNS, Vibrand Research and Yellowwood.

A total of 26 participants took part in the study, representing 15 marketing research firms across South Africa (sampling units). Each sampling element was selected by means of a non-probability purposive sampling method meaning that the researchers deliberately chose each sampling element to fit the criteria, expecting that they are involved with, or have an influence on, quantitative reporting processes and that they hold positions such as client service director or manager (Churchill \& Iacobucci 2010:286).

The researchers conducted in-depth interviews of 20 to 30 minutes with each participant and used a semi-structured interview guide to collect the data. The interview guide included a discussion on general quantitative reporting practices and an in-depth exploration of storytelling. Each interview was recorded and transcribed and the researchers took field notes. Upon completion, the Morse and Field (1996) approach was used to analyse the data. This approach has four steps where the researchers seek to achieve comprehension by gathering sufficient data to be able to write a detailed account of the collected information. Hereafter, when saturation is reached data patterns are categorised according to thematic meanings to form a theory and are then placed in the context of established knowledge.

During the comprehension step, data analysis began through the transcribing, checking, correcting and coding of interviews and field notes (De Vos 1998:341). To achieve saturation, inter-participant analysis was used; here the researchers compared transcripts (line-by-line analysis of each interview transcript) across participants to identify similarities and differences (Burden \& Roodt 2007:15; Morse 
\& Field 1996:105). Based on this analysis, three interpretation categories were identified: the use of quantitative reporting, the use of storytelling and barriers to using storytelling. The researchers transferred participants' responses in each of these interpretation categories into an Excel spreadsheet where colour codes were used for coding. In Step 3, the researchers used literature and the gathered information to theorise about the use of storytelling in quantitative research reports so as to place the results in the context of the established knowledge (De Vos 1998:342). This was used to identify where the results supported literature and where it could claim unique contributions.

\section{Trustworthiness}

It was the researchers' aim to deliver truthful results and to limit error in the qualitative research design by focusing on achieving trustworthiness throughout the research process. To achieve this, Guba's (1981:75-91) model of trustworthiness was applied in this study; this involved checking the four criteria of trustworthiness: truth value, applicability, consistency and neutrality.

Truth value was accomplished through member checking, prolonged engagement and by selecting a purposeful sample (Lincoln \& Guba 1985:302, 314; Rolfe 2006:305, 307). Member checking allows for sharing participants' viewpoints with other members of the sample so as to clear up misunderstandings and to ensure findings are consistent with their experience (Roberts, Priest \& Traynor 2006:43, 44). Once the data was analysed, the researchers discussed the research results with two of the participants so as to check the truth value of the analysis. Prolonged engagement is defined as the investment of sufficient time in the subject matter to achieve certain purposes (Streubert \& Carpenter 1995:25). The researchers were involved with the topic under study since 2008 and involved with the academic literature for two years. A purposeful sample was achieved by only including experts with knowledge and experience about the research topic (quantitative research reports).

Applicability was accomplished by applying scientific analysis, recording of field notes, peer checking, member checking and using low inference descriptors (direct verbatims) (Appleton 1995:995, 996; Rolfe 2006:305, 307). The researchers repeatedly referred back to the in-depth interview data when coding and developing themes for each interpretation category during the data analysis, specifically checking for reasons why the data should not be trusted so as to accomplish scientific analysis (intensive engagement with the data) (Roberts et al. 2006:43, 44). The researchers comprehensively recorded field notes of each indepth interview and included a reflective synopsis of what was experienced and learnt in each interview directly after each interview had been conducted. Peer checking involves using an independent experienced qualitative researcher to ensure that the researchers have analysed the data correctly and check whether they arrive at the same conclusions (Rolfe 2006:305, 307). At the end of the data analysis, the researchers submitted all transcripts and the findings to an experienced qualitative researcher, to compare analysis and to determine if she believed the same findings were true. Low inference descriptors refer to using descriptions very close to participants' direct account to demonstrate that findings are grounded in the data, such as the use of verbatim words (Roberts et al. 2006:44). Where possible, the researchers included verbatim responses as evidence to support or not support propositions, and also avoided only picking the best examples to support analysis.

Consistency was achieved by having an extended timeframe of fieldwork, recording a decision trial, using a standard interview guide, conducting pilot interviews, recording interviews, transcribing interviews and also through scientific analysis (Lincoln \& Guba 1985:302, 314). Extended fieldwork requires the researcher to spend a sufficient amount of time in the field to ensure confidence that data patterns are stable (Johnson 1997:283, 286). The researcher spent a month and a half in the field conducting 26 in-depth interviews; this is considered to be a sufficient timeframe for the required sample. A decision trial requires detailing and recording each decision taken in the research process (Rolfe 2006:305). The researchers clearly described the methodology, explaining and justifying what was done and why it was done. The interview guide was standardised to increase consistency of the data collected. Through pilot interviews the interview guide is tested before actual interviewing commences; all aspects of the interview guide were tested on two qualifying sampling elements (Malhotra \& Birks 2006:345). The researchers used a Dictaphone to record all in-depth interviews to provide verbatim accounts of conversations and an extensive account of the interaction between the researchers and participants. Each audio interview was transcribed to typed text format; the researchers used an independent professional firm (WORDZ2INK) to transcribe each in-depth interview.

Neutrality was accomplished by leaving a decision trial, reflexivity and negative case sampling (Lincoln \& Guba 1985:302, 314; Roberts et al. 2006:44). Reflexivity requires the researchers to engage in self-reflection about bias so as to monitor their bias (Appleton 1995:997). The researchers tried to overcome interview bias by maintaining a neutral stance and not presenting their own perceptions during data collection. Negative case sampling involves looking at and examining examples that disconfirm the researchers' expectations and provisional explanations (Johnson 1997:283, 284). The researchers avoided defending proposed results by searching and examining specific examples that disproved their propositions.

\section{Findings of the research Participants' view of quantitative reporting}

Even though the results of the study are qualitative in nature, Figure 1 provides an in-depth visual presentation of the findings of participants' view of quantitative reporting. Of the 26 participants, 17 agreed that actionable research reports need to be delivered to clients. The word 'actionable' 
was used to indicate that quantitative research results are translated to speak to clients' business issues. Nine of the 26 participants referred to this as the 'so what?' of the research. This means that marketing research firms focus quantitative research reports on the business implications of the research or the indication of specific action steps for the client. To a lesser extent, participants also indicated that the quantitative reporting of marketing research firms they work for is focused on storytelling $(n=6)$ or data integration from different sources or quality $(n=5)$.

\section{Use of storytelling}

A total of 25 of the 26 participants stated that the marketing research firm where they work uses storytelling in quantitative reports in some form. They also indicated that storytelling is a critical aspect of quantitative reporting. The participant who does not use storytelling is well aware of the concept of storytelling, but suggests that a storytelling approach is not fitting for the types of clients and projects that their marketing research firm works on. The participant indicated that these clients are predominantly in operations (as opposed to marketing, branding or on the executive board) and all projects are highly tactical or operational in nature.
Furthermore, only six participants did not spontaneously refer to the importance of storytelling in quantitative reports.

As indicated in Figure 2, most participants $(n=16)$ use storytelling as a way to report research results in a specific order. This implies that research results are not necessarily reported in the same order as that in which questions appear on the questionnaire; in other words, question 2 does not need to follow question 1 , question 3 does not need to follow question 2. Further to this, participants $(n=11)$ added that storytelling is used to report research results in a logical manner with a beginning, middle and end. In addition, participants $(n=11)$ also felt that storytelling means that the research results are structured around answering the client's business question. Participants indicated that this means that data is chosen and reported in such a way that it answers the business question throughout the quantitative research report. Further to this, some participants indicated that a story is conclusion driven $(n=9)$ and few specified that it ensures that a golden thread is present throughout the research results $(n=6)$.

Further to this, participants $(n=20)$ were in agreement that storytelling is of critical importance, mainly because it

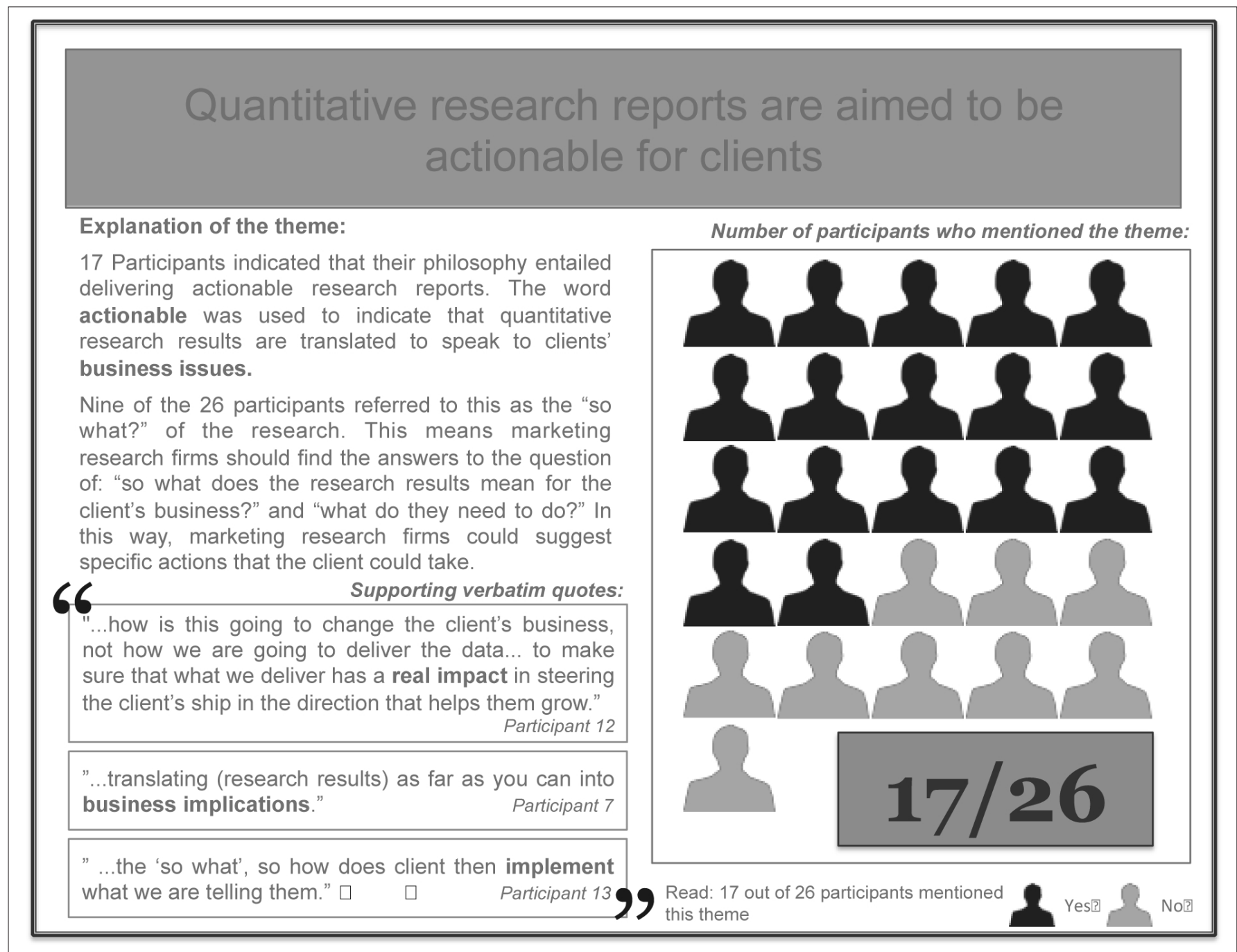

Source: Researchers own construct

FIGURE 1: Participants' view of quantitative reporting. 
forces the marketing research firm to think of the research finding implications (referred to as the 'so what?') and it helps the marketing research firm in distilling what the most important information for the client is. However, participants $(n=15)$ indicated that when quantitative research results are reported as stories, they tend to be shorter and more focused compared to other quantitative reports. Consequently, clients usually require the 'unused' data and information in another format for reference purposes. Marketing research firms therefore typically supply clients with either a full data book or appendix containing all the data together with a shortened version of the 'story' report.

\section{Barriers to using storytelling}

Participants reported several barriers in the use of storytelling. These barriers, as indicated in Figure 3, include:

- Skills: Storytelling is seen as a hard-earned skill that comes with experience. Junior-level staff often do not have sufficient storytelling skills $(n=9)$.

- Client relations: Storytelling becomes difficult if the marketing research firm does not know the client's business and if clients do not trust the marketing research firm to deliver the appropriate research results $(n=9)$.
- Confidence: Storytelling requires the researcher to be confident in the research results' story; without confidence researchers' battle to deliver the story convincingly $(n=8)$.

- Time: The storytelling process is time intensive. Large amounts of data and information need to be distilled to find the appropriate story that answers the client's business question $(n=8)$.

In an attempt to overcome some of these barriers, six participants indicated that the marketing research firm that they work for makes use of a 'formula' or 'model' to help the marketing research firm to adopt storytelling in quantitative reports.

In conclusion, literature acknowledged the importance of storytelling in quantitative reporting, but not to the extent that the empirical main study has indicated. All participants were aware of storytelling and only one participant did not place emphasis on the use of storytelling in quantitative reports. The barriers to adopting storytelling identified in the empirical study were skill shortages (inexperience), poor client relationships and the time it requires to compile stories.

\section{Storytelling is used to deliver actionable research results in a logical format}

\section{Explanation of the theme:}

When participants were asked to define storytelling 16 participants indicated that storytelling is about reporting research results in a specific order (not necessarily in the questionnaire order).

Almost half of participants (11) indicated that storytelling is concerned with reporting the research results in such a way that it answers the client's business question(s).

\section{6}

Supporting verbatim quotes:

anyone can churn out a report but you need to structure the report in such a way that it tells a story."

Participant 2

..making sure that you've got all the pieces that are relevant and then putting it together in a way that means that there's a beginning a middle and an end..

identify the most meaningful facts and what does that mean for their business and that's the key to storytelling."

Participant 26

"Storytelling is based on the business question."

Participant
Number of participants who mentioned the theme:

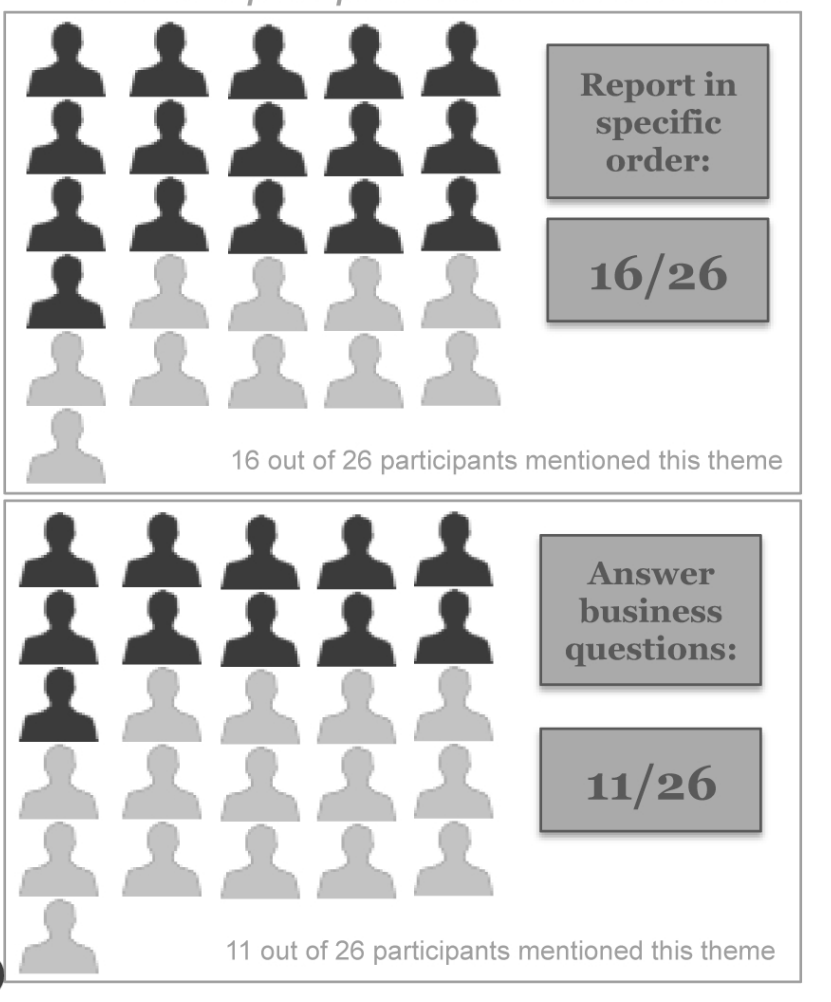




\section{A variety of barriers limit the use of storytelling}

\section{Explanation of the theme:}

Many barriers to storytelling are evident and responses are varied. The highest mentions included:

- Individual skill: storytelling is seen as a hard earned skill that comes with experience (9 participants).

- Poor client relationship: storytelling becomes difficult if the marketing research firm does not know the client's business and if clients do not trust the marketing research firm to deliver the appropriate research results (9 participants).

- Lack of confidence: storytelling requires the researcher to be confident in the research results' story; without confidence researchers battle to deliver the story (8 participants).

- Time intensive: stories take a lot of time to compile since the marketing research firm still needs to have extensive knowledge of the data (8 participants).

66 Supporting verbatim quotes:

think inexperience...some people will never ever get to that. I think also inability to see the bigger picture."

Participant 23

..there has to be a lot of trust on the part of the client that we have pulled out the relevant story."

Participant 14

"I think it's knowing what to leave behind and be confident enough to stand up there and say this is actually a ten page story, there's backup their client but this is about being confident enough in yourself."

Participant 17

"There's no shortcut way to finding the story." Participant 3
Number of participants who mentioned the theme:
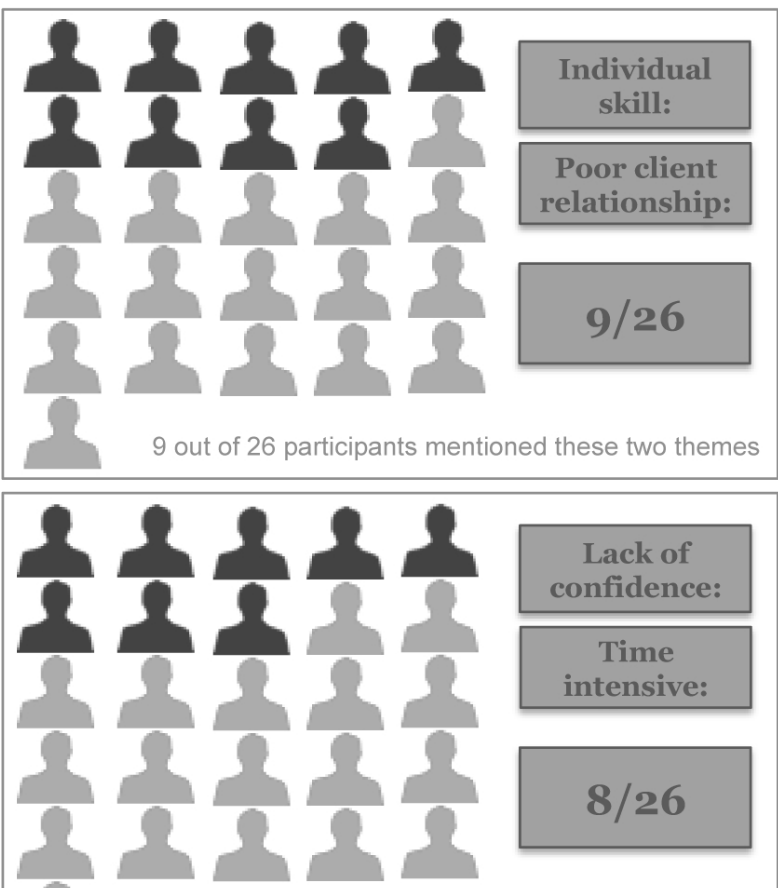

Time

intensive:

$8 / 26$

Source: Researchers own construct

FIGURE 3: Barriers to using storytelling.

\section{Discussion and conclusion}

The literature review described that the use of storytelling is an imperative of actionable reporting. This is reflected in the empirical results, which indicate that all except one participant claimed to use storytelling in quantitative research reports. Several implications of the results are evident.

\section{Use of storytelling}

- General practice: A key focus area of actionable reporting is the use of storytelling. This implies that it is no longer just a 'theoretical' demand, but it is acknowledged by marketing research firms as essential to the delivery of research reports.

- Questions differentiation: The fact that almost all participants claim the use of storytelling leads to the question of whether a standardised approach across marketing research firms is used or not. And, if not, how do marketing research firms differentiate their research report (story) from other marketing research firms?

- Suitability: There is some suggestion that storytelling is more suitable for particular clients and for operational or tactical projects. This implies that the use of storytelling is not applicable to all marketing research firms (dependent on the client base and service offering).

- Application: The results imply that the majority of marketing research firms have the philosophy of using storytelling in all reports but fail to confirm whether storytelling is consistently applied within the firm. This could bring into question whether storytelling is applied in delivering the research report or whether it is just considered an ideal method for reporting.

\section{Barriers to using storytelling}

- Experience: It is clear from the results that adequate experience is needed to be able to deliver reports in a storytelling manner. The question then arises how junior researchers can be facilitated in building satisfactory experience in storytelling.

- Standardisation: It seems as if marketing research firms are trying to standardise the storytelling process for researchers (six participants indicated the use of a storytelling formula or model), which could indicate that some level of training is necessary to develop researcher skills beyond data literacy. 
- Strong client relationships: It is evident that strong client relationships enable researchers to deliver better storytelling. At the heart of strong relationships is a thorough understanding of the client's business. When marketing research firms have a complete understanding of the client's business and are proactively engaged with it, innovative and right actions can be recommended in the research report (Bain 2012a).

It is therefore recommended that marketing research firms continue to focus on and grow their storytelling capabilities. Various actions could be taken to decrease the time needed to compile stories, whilst simultaneously growing researcher skills and experience. Marketing research firms may consider any of the following recommendations:

\section{Use of storytelling}

- Follow best practice: The following key principles should be followed when compiling stories:

- Simplicity is key.

- It should be engaging and interactive.

- It should be tailored to the client audience.

- It should create a context against which the data can be interpreted.

- It should be supported by reliable data visualisations and should be compelling (i.e. addressing business issues; see Davison 2011; Eloff 2012; Lowell 2011; Silverman 2006).

- Allocate resources: Appoint or allocate a dedicated individual to be responsible for ensuring that storytelling is applied throughout the marketing research firm.

\section{Overcome barriers to using storytelling: Experience}

- Provide training: Develop, implement and use storytelling 'formulas' as guidance for researchers in story creation; train researchers on right-brain thinking and other techniques applicable to storytelling (for example, on story elements like mission, characters, etc.).

- Grow skills: Share good examples of stories in the marketing research firm so as to expose employees to best practice examples in order that they might learn any 'tips or tricks'.

- Experiment: Take courage and experiment with stories that are less ordinary and more 'brave' (within business purpose). Attempt this with clients who are prone to experiment and with whom the marketing research firm have a good and standing relationship.

\section{Overcome barriers to using storytelling: Client relationship}

- Build strong client relationships: The top enabler of strong relationships is to understand the clients' business. This can be achieved by collaborating with clients on insight generation, asking the 'so what?' question (what the research means to their business and how it impacts business activities and decisions), ensuring that clients perceive researchers as a strategic asset and integrating data from various sources (Cambiar 2011:7).

Limited options are available to directly overcome the time intensity barrier associated with storytelling. It will remain essential for researchers to fully immerse themselves in the data and client's business in order to deliver good stories. This being said, a researcher with sufficient experience in storytelling and with good client relationships will most likely take a shorter time to arrive at the story compared to a researcher with limited experience and a poor client relationship.

\section{Limitations and future research}

The main limitation of this study is that the sensitive and confidential nature of the topic under investigation may have caused participants to be reserved in sharing valuable knowledge with the researchers. The practical effect of this was that some information could have been withheld from the researchers, which could have led to deeper insights and possible recommendations. Furthermore, smaller revenue contributing marketing research firms were hesitant and refused to participate and are therefore slightly underrepresented in this study. Furthermore, a qualitative sampling method was used, limiting the generalisation of results to the sample and not the population as a whole.

Further research could be done in conducting a gap analysis of senior marketing research firm employees' (like those interviewed) and junior marketing research firm employees' use of storytelling. The aim would be to determine any differences in the understanding and use and application of storytelling. Research can also be conducted to determine specific methods for overcoming the barriers of using storytelling.

\section{Acknowledgements Competing interests}

The authors declare that they have no financial or personal relationships that may have inappropriately influenced them in writing this article.

\section{Authors' contributions}

V.M. (University of Johannesburg) was the master's student whose research dissertation this article is based on. D.J.P. (University of Johannesburg) and C.F.D.M. (University of Johannesburg) were the supervisors for the study and assisted in the writing of the article. C.F.D.M. assisted with the literature review and recommendations sections. D.J.P. assisted with the methodology, statistical analysis and recommendations sections.

\section{References}

Appleton, J.V., 1995, 'Analysing qualitative interview data: Addressing issues of validity and reliability', Journal of Advanced Nursing 22, 993-997. http://dx.doi. org/10.1111/j.1365-2648.1995.tb02653.x 
Appleton, E., 2011, Should research agencies be paid for the value of their insights? viewed 31 December 2011, from http://www.greenbookblog.org/2011/10/25/ viewed 31 December 2011, from http://www.greenbookblog.o
should-research-agencies-be-paid-for-the-value-of-their-insights/

Bain, R., 2011, Picture perfect, viewed?? March 2011, from http://research-live. com/4004897.article

Bain, R., 2012a, Time to put your foot down, viewed 11 May 2012, from http:// research-live.com/time-to-put-your-foot-down/4003435.article

Bain, R., 2012b, The battle of substance and style, viewed 11 January 2011, from http://www.research-live.com/4007026.article

Bizcommunity, 2011, Marketing research companies in South Africa, viewed 29 March 2011, from www.bizcommunity.com/Companies/196/19/service-Marketing\%20 Research.html

Bosworth, M. \& Zoldan, B., 2012, What great salespeople do: The science of selling through emotional connection and the power of story, McGrawHill Companies, Inc., Hoboken, NJ.

Burden, J. \& Roodt, G., 2007, 'Grounded theory and its application in a recent study on organisations redesign: Some reflections and guidelines', SA Journal of Human Resource Management 5(3), 11-18.

Cambiar, 2011, The future of research report (October 2011), viewed 20 January 2011, from http://www.consultcambiar.com/wp-content/uploads/2010/06/ CambiarFutureofResearchReport_2011.pdf

Cant, M., Gerber-Nel, C., Nel, D. \& Kotzé, T., 2008, Marketing research, 2nd edn., Van Schaik Publishers, Pretoria.

Carr, A.N. \& Ann, C., 2011, 'The use and abuse of storytelling in organizations', Journal of Management Development 30(3), 236-246. http://dx.doi. org/10.1108/02621711111116162

Carter-Black, J., 2007, 'Teaching cultural competence: An innovative strategy grounded in the universality of storytelling as depicted in African and AfricanAmerican storytelling traditions', Journal of Social Work 43, 11-32.

Churchill, G.A. \& lacobucci, D., 2010, Marketing research: Methodological foundations, 10th edn., Cengage Learning Independence, KY.

Czarnecki, K., 2009, Storytelling in context. In digital storytelling in practice, Library Technology Reports, Chicago, IL.

Davison, L., 2011, 'As stimulating as black coffee - communications that are hard to sleep after', paper presented at ESOMAR Annual Congress, Amsterdam, The Netherlands, September.

De Vos, A.S., 1998, Research at grassroots: A primer for the catering professions, Van Schaik Publishers, Pretoria.

Deloitte, 2011, Tech Trends 2011 (Electronic Version), viewed 28 March 2011, from http://www.deloitte.com/us/2011techtrends\#download

Digit, 2011, The power of data visualisation, viewed 30 March 2011, from http://www. digitlondon.com/downloads/casestudies/the_power_of_data_visualisation.pdf

Dowsett, C., 2012, Escaping the commoditisation trap, viewed 15 March 2012 from http://www.research-live.com/comment/escaping-the-commoditisationtrap/4007045.article

Doyle, A. \& Tharme, A., 2011, Do researchers understand visual design?, viewed 25 March 2011, from http://www.research-live.com/features/do-researchersunderstand-visual-design?/4004766.article

Eloff, M., 2012, 'A picture is worth a thousand -numbers', paper presented at SAMRA Conference 2012, Johannesburg, South Africa, 16-17 August.

Few, S., 2007, Data visualization past, present, and future, viewed 07 March 2011 from http://www.perceptualedge.com/articles/Whitepapers/Data_Visualization. pdf

Few, S., 2011, 'The chartjunk debate. A close examination of recent findings', Visual Business Intelligence newsletter April/May/June. Available from http://www. perceptualedge.com/articles/visual_business_intelligence/the_chartjunk perceptual
debate.pdf

Florence, C., 2013, A matter of fact, not fiction, viewed 10 April 2013, from http:// www.research-live.com/comment/a-matter-of-fact-not-fiction/4009220.article

Ghoshal, N.D., 2011, 'Storytelling: Co-create a tale', Admap, October, pp. 36-37.

GreenBook, 2011, Research industry trends report, viewed 30 November 2011, from http://www.greenbookblog.org/grit-fall-2011/

Grimshaw, C., 2011, 'From the editor: Data is the new black', Admap, September, p. 3.

Guba, E.G., 1981, 'Criteria for assessing the trustworthiness of naturalistic inquiries', Educational Resources Informations Centre Annual Review Paper 29, 75-91.

Hamburger, S. \& Lawry, P., 2008, 'Storytelling with international millionaires - a creative approach to research', paper presented at ESOMAR Annual Congress 2008, Montreal, Canada, 22-24 September.
James, C. \& Minnis, W.C., 2004, 'Organizational storytelling: It makes sense', Business Horizons 47(4), 23-32. http://dx.doi.org/10.1016/S0007-6813(04)00045-X

Johnson, R.B., 1997, 'Examining the validity structure of qualitative research', Education 118(2), 282-292.

Kaidi, Z., 2012, Data visualization, viewed 23 August 2012, from http://www.cs.uic. edu/ kzhao/Papers/00_course_Data_visualization.pdf

Lewis, I., 2010, High-impact research - The new strategic partner, viewed 10 November 2011, from http://www.amcham.org.eg/mkg_files/Research-WorldMarch-2010-High-Impact-Research.pdf

Lincoln, Y.S. \& Guba, E.G., 1985, Naturalistic inquiry, SAGE Publications, Beverly Hills, CA. Lowell, J., 2011, 'Data integration: Visualise the data', Admap, September, pp. 26-28. Mahmoud, O., 2004, 'Market research? Come on, this is serious!', paper presented at ESOMAR Annual Congress, Lisbon, Portugal, 19-22 September.

Malhotra, N.K. \& Birks, D.F., 2006, Marketing research: An applied approach, 2nd edn., Pearson Education Inc, London.

McCall, D.M., Rabson, J. \& Dimopoulos, I.J., 2004, 'Getting research noticed at the corporate table', paper presented at ESOMAR Annual Congress, Lisbon, Portugal, 19-22 September.

Micu, A.C., Dedeker, K., Lewis, I., Moran, R., Netzer, O., Plummer, J. et al. 2011, 'The shape of marketing research in 2012', Journal of Advertising Research 51(1), 213221. http://dx.doi.org/10.2501/JAR-51-1-213-221

Mittens, M., Abratt, R. \& Christie, P., 2011, 'Storytelling in reputation management: The case of Nashua Mobile South Africa', Management Decision 49(3), 405-421. http://dx.doi.org/10.1108/00251741111120770

Moran, R., 2010, StrategyOne: Insight's future: From market research to strategic insights, viewed 11 November 2011, from http://www.strategyone.com/ documents/InsightsFutureBrochure.pdf

Morse, J.M. \& Field, P.A., 1996, Nursing research: The application of qualitative approaches, 2nd edn., Stanley Thornes Ltd, Cheltenham. http://dx.doi. org /10.1007/978-1-4899-4471-9

Precourt, G., 2010, 'Why marketing research must change: Rubinson issues call to insight action at ARF assembly', Admap, October.

Roberts, P., Priest, H. \& Traynor, M., 2006, 'Reliability and validity in research', Nursing Standard 20(44), 41-45. http://dx.doi.org/10.7748/ns2006.07.20.44.41.c6560

Rolfe, G., 2006, 'Validity, trustworthiness and rigour: Quality and the idea of qualitative research', Journal of Advanced Nursing 53(3), 304-310. http://dx.doi. org/10.1111/j.1365-2648.2006.03727.x

Segel, E. \& Heer, J., 2010, Narrative visualization: Telling stories with data, viewed 11 June 2012, from http://vis.stanford.edu/files/2010-Narrative-InfoVis.pdf

Shaw, S., 2010, 'Communicating creatively: From digital media to stains on the bedroom floor', paper presented at Market Research Society Annual Conference, 22-23 March.

Silverman, L.L., 2006, Wake me up when the data is over, John Wiley \& Sons, Inc., Hoboken, NJ.

Southern African Marketing Research Association (SAMRA), 2010, Marketing research services in Southern Africa, viewed 29 March 2011, from http://www.samra. co.za/wp-content/uploads/2010/05/classifieds-2010.pdf

SAMRA, 2011, Market research services in Southern Africa, accessed 16 January 2012, from http://www.samra.co.za/wp-content/uploads/2010/05/Classifieds2012, from

Streubert, H.J. \& Carpenter, DR., 1995, Qualitative research in nursing, JB Lippincott Company, Philadelphia, PA.

Thun, S. \& Brandt, D.R., 2007, 'Transforming the marketing research industry', paper presented at ESOMAR Annual Congress, Berlin, Germany, 16-19 September.

TNS, 2004, 'TNS and the research industry in South Africa', unpublished presentation to V. Maritz, Johannesburg, South Africa.

TNS, 2010, The storytelling project Volume 1, Internal training material, Author, London.

Tobin, P.K.J. \& Snyman, R., 2008, 'Once upon a time in Africa: A case study of storytelling for knowledge sharing', Aslib Proceedings 60(2), 130-142. http:// dx.doi.org/10.1108/00012530810862464

Van Slooten, W. \& Verheggen P., 2011, 'Market research reloaded', paper presented at ESOMAR Annual Congress, Amsterdam, the Netherlands, 18-21 September.

Von Bormann, T., 2000, 'A question of change', Marketing Mix Journal 18(02), 32-37.

White, H., 2011, Top tips on data visualisation, viewed 24 April 2011, from http:// news.bbc.co.uk/go/pr/fr/-/2/hi/school_report/9365675.stm

Zikmund, W.G. \& Babin, B.J., 2010, Essentials of marketing research, 4th edn., SouthWestern Cengage Learning, Independence, KY. 